\title{
Behuria, Bertolonia, Cambessedesia, Huberia e Mouriri, e chave para identificação de gêneros de Melastomataceae no Estado do Paraná
}

Behuria, Bertolonia, Cambessedesia, Huberia and Mouriri, and identification key for the genera of Melastomataceae in the State of Paraná

\author{
Renato Goldenberg ${ }^{1,3}$, Lucas Freitas Bacci ${ }^{2}$ \& Thuane Bochorny ${ }^{2}$
}

\begin{abstract}
Resumo
A família Melastomataceae possui 22 gêneros e 150 espécies no estado do Paraná. Tratamentos com descrições e chaves de identificação já foram publicados para 17 destes gêneros. Neste trabalho, são apresentados os tratamentos taxonômicos dos cinco gêneros faltantes, com nove espécies: Behuria insignis, Bertolonia acuminata, B. margaritacea, B. mosenii, B. paranaensis, Cambessedesia espora, C. hilariana, Huberia semiserrata e Mouriri chamissoana. Também é apresentada uma chave de identificação para os gêneros de Melastomataceae ocorrentes no Paraná, além de ilustrações dos gêneros apresentados neste trabalho.

Palavras-chave: Angiospermas, flora, Salpinga, taxonomia.
\end{abstract}

\begin{abstract}
Melastomataceae has 22 genera and 150 species in the state of Paraná. Treatments with descriptions and identification keys have already been published for 17 genera. In this work, we presented a monograph for the last five genera, with nine species: Behuria insignis, Bertolonia acuminata, B. margaritacea, B. mosenii, B. paranaensis, Cambessedesia espora, C. hilariana, Huberia semiserrata and Mouriri chamissoana. We also present an identification key for all the genera of Melastomataceae occurring in Paraná.
\end{abstract}

Key words: Angiosperms, flora, Salpinga, taxonomy.

\section{Introdução}

A família Melastomataceae possui 22 gêneros e 150 espécies no Paraná (Goldenberg 2014; Meyer \& Goldenberg 2014), ocorrentes em praticamente todos os tipos de vegetação do estado. Estas espécies vêm sendo objeto de estudo há cerca de 10 anos, e destes gêneros, 17 já tiveram monografias publicadas ou em vias de publicação (Goldenberg 2004; Goldenberg et al. 2005; Camargo \& Goldenberg 2007; Camargo et al. 2009; Meyer et al. 2010; Meyer \& Goldenberg 2012; Meyer et al. 2012; Goldenberg et al. 2012a; Goldenberg et al. 2015). Os gêneros que faltam para completar os estudos para a família são cinco: Mouriri Aubl., Bertolonia Raddi, Behuria Cham., Cambessedesia DC. e Huberia DC. À exceção dos três últimos, estes gêneros não têm relações próximas entre si, e a opção por publicá-los em conjunto é meramente de ordem prática.
Mouriri é o único gênero no estado pertencente à subfamília Olisbeoideae (Stone 2006), previamente citada como subfamília Memecyloideae (Cogniaux 1891; Morley 1976) ou mesmo como uma família, Memecylaceae, distinta de Melastomataceae (Renner 1993; Clausing \& Renner 2001). Difere das plantas pertencentes a Melastomoideae (i.e., todas as demais Melastomataceae ocorrentes no estado) pelas folhas com venação não acródroma, e pela presença de uma glândula no dorso da antera (Morley 1976). Estas glândulas produzem óleo, e estão relacionadas à polinização por abelhas (Buchmann 1987).

Bertolonia é um gênero de plantas herbáceas, que apresentam frutos obtriquetras (i.e., com ápice anguloso, triangular; Baumgratz 1990). Outros gêneros de plantas herbáceas com frutos obtriquetras, como Salpinga Mart. ex DC., Monolena Triana ex Benth. \& Hook.f. e Triolena Naudin foram tradicionalmente considerados como relacionados a

\footnotetext{
${ }^{1}$ Universidade Federal do Paraná, Centro Politécnico, Setor de Ciências Biológicas, Depto. Botânica, sl. 447, C.P. 19031, 81531-970, Curitiba, PR, Brasil.

${ }^{2}$ Universidade Estadual de Campinas, Pós-graduação em Biologia Vegetal, Depto. Botânica, R. Monteiro Lobato 255, 13083-862, Campinas, SP, Brasil.

${ }^{3}$ Autor para correspondência: rgolden@ufpr.br
} 
Bertolonia (Clausing \& Renner 2001), mas trabalhos sobre filogenia com marcadores moleculares vêm mostrando que Bertolonia pertence a uma linhagem distinta das demais (Goldenberg et al. 2012b; Goldenberg et al., in press). Salpinga margaritacea (Naudin) Triana é a única espécie de Salpinga que vem sendo registrada para a Mata Atlântica (Goldenberg et al. 2009; Baumgratz 2015) e, mais recentemente, para o Paraná (Meyer et al. 2012), mas as mesmas referências sobre filogenia mostram que esta espécie não tem relação com as demais de Salpinga. Considerando as evidências de que Salpinga margaritaceae é relacionada a espécies de Bertolonia, e não de Salpinga, esta espécie será tratada, neste trabalho, como pertencente a Bertolonia.

Cambessedesia, Behuria e Huberia pertencem a um clado para o qual ainda não há designação de tribo (Goldenberg et al. 2012b). Este clado é formado por gêneros pequenos a médios, todos do leste do Brasil, até agora sem evidências de uma sinapomorfia morfológica. Cambessedesia era tradicionalmente posicionado na tribo Microlicieae mas não está filogeneticamente relacionado a esta (Fritsch et al. 2004; Rodrigues 2009). Os dois últimos eram tradicionalmente incluídos na tribo Merianieae (Baumgratz 2004; Tavares 2005), juntamente com Dolichoura Brade e Merianthera Kuhlm. (Renner 1993), mas não tem relação filogenética próxima com os demais gêneros da tribo, como Meriania Sw., Graffenrieda DC. e Adelobotrys DC., todos estes com diversidade mais pronunciada na Amazônia e Andes (Goldenberg et al. 2012b; Schulman \& Hyvonen 2003).

Neste trabalho é apresentada uma chave de identificação para gêneros de Melastomataceae ocorrentes no Paraná, e o tratamento taxonômico com chaves de identificação, descrições dos gêneros e espécies, comentários, distribuição geográfica, listagens de materiais examinados e ilustrações para todas as espécies dos gêneros Behuria, Bertolonia, Cambessedesia, Huberia e Mouriri no estado.

\section{Materiais e Métodos}

As exsicatas analisadas neste trabalho foram provenientes dos herbários FUEL, MBM e UPCB (siglas segundo Thiers, continuamente atualizado). As amostras listadas como "material selecionado" ou "material examinado" foram exclusivamente provenientes do estado do Paraná e serviram de base para as descrições. O material foi selecionado quando havia mais de uma coleta no município. Neste caso, todas as amostras podem ser conferidas na lista de exsicatas, ao final do trabalho. As amostras listadas como "material adicional examinado" foram provenientes de outros estados, quando houve necessidade de mais materiais para complementar as descrições.

A chave de gêneros foi baseada em trabalhos previamente publicados. Chaves de identificação de espécies e descrições para Aciotis, Acisanthera, Marcetia, Microlepis, Pterolepis e Siphanthera podem ser encontradas em Meyer \& Goldenberg (2012), para Chaetostoma, Lavoisiera, Microlicia, Rhynchanthera e Trembleya em Goldenberg et al. (2015), para Clidemia, Pleiochiton e Ossaea em Goldenberg et al. (2005), para Leandra em Camargo \& Goldenberg (2007) e Camargo et al. (2009), para Miconia em Goldenberg (2004), e para Tibouchina em Meyer et al. (2010).

Para mais informações sobre os táxons tratados aqui, como listagens de sinonímias e tipos, ver Morley (1976), Tavares (2005), Baumgratz (1990), Baumgratz (2004) e Rodrigues (2009). Estes mesmos autores, e mais Martins et al. (2009), e Baumgratz et al. (2015) foram consultados para informações sobre distribuição geográfica. Os dados sobre fenologia foram obtidos a partir de exemplares de herbário, e apenas aqueles coletados no Paraná. Para dados sobre o ambiente físico e vegetação do Paraná, ver Maack (2012) e Labiak (2014).

\section{Resultados e Discussão}

\section{Chave de identificação de gêneros de Melastomataceae no estado do Paraná}

1. Folhas com venação broquidódroma; estame com conectivo provido de uma glândula no dorso; fruto baga..... Mouriri

1'. Folhas com venação acródroma; estame com conectivo desprovido de glândula; fruto cápsula ou baga.

2. Ovário livre no interior do hipanto; fruto cápsula.

3. Cápsula obtriquetra Bertolonia

3'. Cápsula de outra forma, não obtriquetra.

4. Flores isostêmones, estames férteis 4-5 (mais 5 estaminódios em Rhynchanthera).

5. Flores 4-meras Siphanthera 
5'. Flores 5-meras

Rhynchanthera

4'. Flores diplostêmones, estames férteis 8-12.

6. Flores com pétalas amarelas ou vermelho-alaranjadas com base amarela

Cambessedesia

6'. Flores com pétalas brancas, rosadas, lilases ou roxas, nunca amarelas ou vermelho-alaranjadas.

7. Estames com conectivo dorsalmente apendiculado.

8. Flores 4-meras

Huberia

8'. Flores 6-meras

Behuria

7'. Estames com conectivo inapendiculado ou ventralmente apendiculado.

9. Hipanto externamente com uma coroa de tricomas no ápice.

Chaetostoma

9'. Hipanto externamente destituído de uma coroa de tricomas no ápice.

10. Ápice da antera rostrado; sementes oblongas, ovóides, não cocleadas.

11. Folhas com pontuações translúcidas; ovário 3-locular..... Microlicia

11'. Folhas sem pontuações translúcidas; ovário 4-6-locular.

12. Folhas 5-15 × 3-7 mm; flores geralmente 6-meras (raramente 5-meras); pétalas lilases ou magentas. Lavoisiera

12'. Folhas 23-50 × 6-16 mm; flores 5-meras; pétalas brancas ou rosadas Trembleya

10'. Ápice da antera atenuado, subulado, truncado, obtuso ou arredondado, não rostrado; sementes cocleadas.

13. Ovário com ápice glabro.

14. Conectivo inapendiculado

Aciotis

14'. Conectivo apendiculado.

15. Folhas planas; estames antessépalos com conectivo longamente prolongado abaixo das tecas Acisanthera

15'. Folhas assoveladas; estames dos dois ciclos com conectivo curtamente prolongado abaixo das tecas Marcetia

13’. Ovário com ápice coroado por indumento.

16. Hipanto externamente com projeções vascularizadas e ramificadas, com tricomas simples Pterolepis

16'. Hipanto externamente sem projeções vascularizadas e ramificadas, glabro ou com tricomas simples, estrelados ou dendríticos.

17. Estames com anteras de ápice subulado combinadas com conectivos com apêndices subulados Microlepis

17'. Estames com anteras de ápice subulado combinadas com conectivos com apêndices curtos, com ápice obtuso ou anteras de ápice truncado combinadas com conectivos com apêndices subulados

Tibouchina

2'. Ovário adnato ao hipanto, total ou parcialmente; fruto baga.

18. Plantas epífitas ou terrestres, neste caso trepadeiras Pleiochiton

18'. Plantas terrestres e eretas ou cespitosas, nunca trepadeiras.

19. Botões com ápice agudo; pétalas com ápice agudo ou acuminado.

20. Inflorescências axilares ou caulifloras Ossaea

20'. Inflorescências terminais ou pseudo-axilares (terminais quando jovens, mas ultrapassadas em tamanho por ramos laterais, quando em frutos) Leandra

19'. Botões com ápice arredondado; pétalas com ápice obtuso, arredondado ou emarginado.

21. Inflorescências axilares ou pseudo-axilares (terminais quando jovens, mas ultrapassadas em tamanho por ramos laterais, quando em frutos); cálice com dentes externos muito desenvolvidos, mais longos do que os lobos internos

Clidemia

21'. Inflorescências terminais, às vezes com ramos adicionais axilares; cálice com dentes externos ausentes ou pouco desenvolvidos, mais curtos do que os lobos internos 


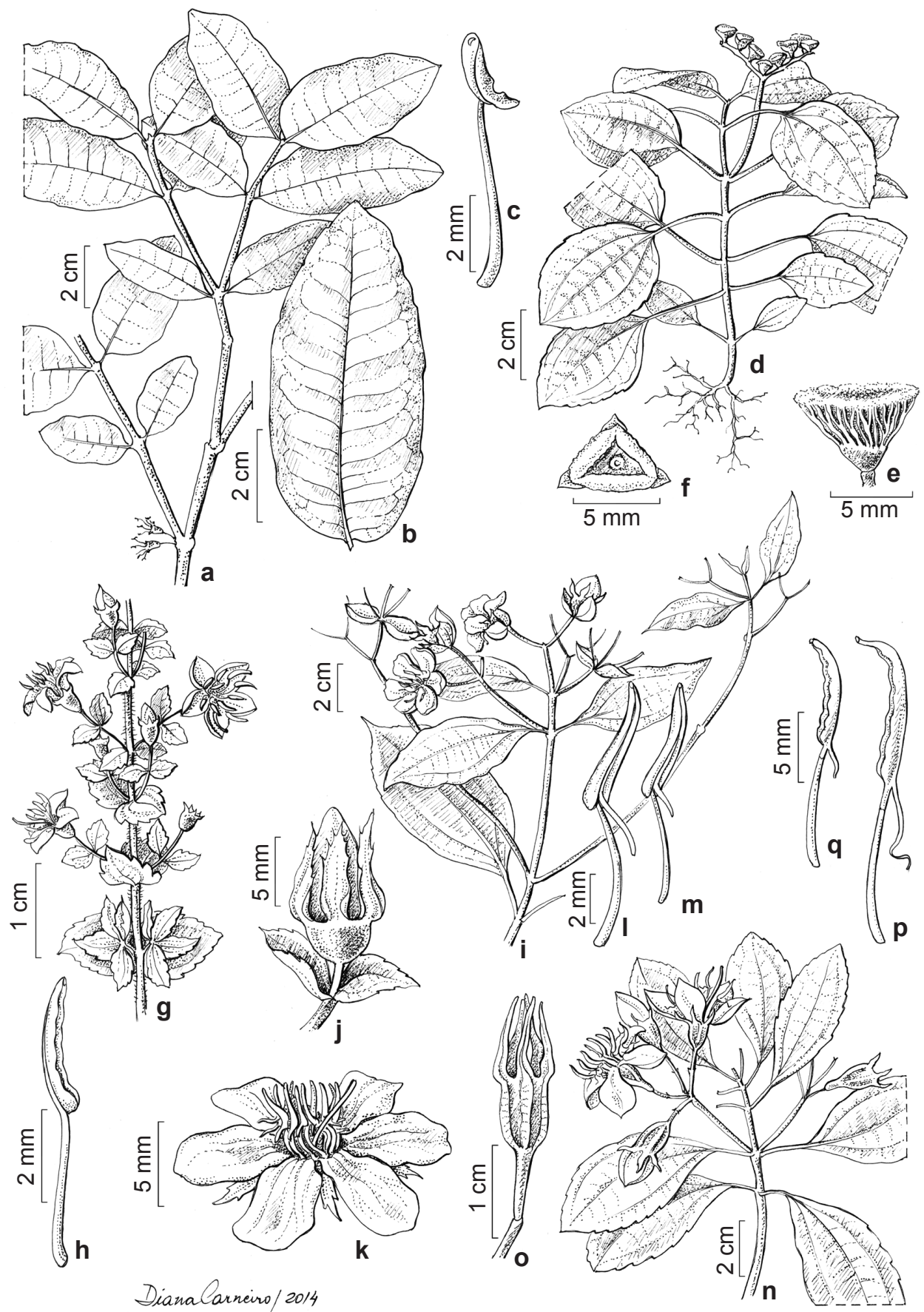

Figura 1 -a-q. Behuria, Bertolonia, Cambessedesia, Huberia e Mouriri no Paraná. a-c. Mouriri chamissoana Cogn. - a. ramo fértil; b. folha, face abaxial; c. estame (Hatschbach 20358). d-f. Bertolonia mosenii Cogn. - d. ramo fértil; e. fruto, vista lateral; f. fruto, vista apical (Caddah 705). g-h. Cambessedesia espora (A.St.-Hil. ex Bonpl.) DC. - g. ramo fértil; h. estame (Hatschbach 13965). i-m. Behuria insignis Cham. - i. ramo fértil; j. botão floral; k. flor; l. estame antessépalo; m. estame antepétalo (Souza 474). n-q. Huberia semiserrata DC. - n. ramo fértil; o. botão floral; p. estame antessépalo; q. estame antepétalo (Meirelles 419). Figure 1 - a-q. Behuria, Bertolonia, Cambessedesia, Huberia and Mouriri in Paraná. a-c. Mouriri chamissoana Cogn. - a. fertile branch; b. leaf, abaxial surface; c. stamen (Hatschbach 20358). d-f. Bertolonia mosenii Cogn. - d. fertile branch; e. fruit, lateral view; f. fruit, apical view (Caddah 705). g-h. Cambessedesia espora (A.St.-Hil. ex Bonpl.) DC. - g. fertile branch; h. stamen (Hatschbach 13965). i-m. Behuria insignis Cham. - i. fertile branch; j. flower bud; k. flower; 1. antesepalous stamen; m. antepetalous stamen (Souza 474). n-q. Huberia semiserrata DC. - n. fertile branch; o. flower bud; p. antesepalous stamen; q. antepetalous stamen (Meirelles 419). 
1. Behuria Cham., Linnaea 9: 376. 1834.

Arbustos com tricomas glandulares, glabrescentes. Folhas com venação acródroma. Inflorescências tirsóides, curtas, apicais. Flores 6-meras, diplostêmones; hipanto glandulosopontuado; cálice simples (desprovido de dentes externos); pétalas brancas, com ápice arredondado; estames 12 , conectivo desprovido de glândula no dorso, com apêndice dorso-basal único, filiforme, antera com ápice atenuado. Ovário parcialmente súpero, com ápice lobado revestido por tricomas glandulares. Frutos capsulares; sementes piramidais.

Behuria é um gênero exclusivo do Brasil, com 15 espécies (Tavares 2005; Baumgratz \& Chiavegatto 2015). Tem distribuição restrita ao domínio de Mata Atlântica no Espírito Santo, Minas Gerais, Rio de Janeiro, São Paulo e Paraná. No Paraná é representado por uma espécie.

1.1 Behuria insignis Cham., Linnaea 9: 377. 1834.

Fig 1i-m

Arbustos 1,5-3 m alt. Folhas com pecíolo 0,5-1,5 mm compr.; lâmina 4-9 × 2-3 cm, lanceoladas, base aguda a agudo-atenuada, ápice agudo ou acuminado, margem ciliada. Tirsóides 4,4-6,5 cm compr., apicais. Flores com pedicelo 1-2,5 cm compr.; hipanto 3,5-4 mm compr.; cálice com lobos ca. $5 \mathrm{~mm}$ compr., persistentes; pétalas $12-14,5 \times 10 \mathrm{~mm}$, brancas, obovadas ou oblongas, ápice arredondado; estames subisomorfos, com filetes ca. $4 \mathrm{~mm}$ compr. (antepétalos) ou ca. $6 \mathrm{~mm}$ compr. (antessépalos), anteras ca. $4,5 \mathrm{~mm}$ compr., apêndice ca. 2,5 mm compr.; ovário $4 \times 2,2 \mathrm{~mm}$, 4-locular., estilete ca. $10 \mathrm{~mm}$ compr. Cápsula $4 \times 6,2$ mm compr.; sementes ca. 1,5-2 mm compr. Material examinado: Antonina, 6.I.1992, G. Hatschbach 56161 (MBM); 25.I.1993, G. Hatschbach 58254 (MBM); 14.I.2014, F.R. Maia 110 (UPCB); 26.I.2015, T. Bochorny 127 (MBM).
Behuria insignis é encontrada somente em São Paulo e Paraná (Tavares 2005; Baumgratz \& Chiavegatto 2015). No Paraná ocorre em floresta pluvial, em encosta de morro, e dela se conhece apenas uma população. Coletada com flores e frutos em janeiro. Behuria insignis pode ser reconhecida pelas flores 6-meras, com pétalas brancas e estames amarelos, estes com apêndices dorsais filiformes.

2. Bertolonia Raddi, Mem. Mat. Soc. Ital. Sci. Modena, Pt. Mem. Fis. 18: 384. 1820.

Ervas ou subarbustos, terrestres, rupícolas ou hemiepífitos, geralmente rizomatosos, glandulosos, glabrescentes, raro glabros. Folhas com venação acródroma. Inflorescências cimosas, escorpioides ou trifloras, longas, apicais. Flores 5-meras, diplostêmones; hipanto glanduloso-pontuado ou com tricomas simples sobre as costelas; cálice bilobado ou simples (desprovido de dentes dorsais); pétalas brancas a róseas, com ápice acuminado a arredondado; estames 10, conectivo desprovido de glândula no dorso, com um ou mais apêndices dorsais arredondados ou bilobados, antera com ápice arredondado. Ovário parcialmente súpero, com ápice glabro ou revestido por tricomas glandulares. Frutos do tipo cápsula obtriquetra, ápice do eixo principal triangular; sementes clavadas ou obovadas.

Bertolonia é um gênero exclusivo do Brasil, com 19 espécies (Baumgratz 2015a; Meyer et al. 2012). Tem distribuição restrita ao domínio de Mata Atlântica no Rio Grande do Norte, Pernambuco, Alagoas, Bahia, Minas Gerais, Espírito Santo, Rio de Janeiro, São Paulo, Paraná e Santa Catarina (Baumgratz 2015). No Paraná é representado por quatro espécies.

\section{Chave de identificação para as espécies de Bertolonia no estado do Paraná}

1. Lâmina foliar densamente pilosa, face adaxial com tricomas 6-12 mm compr.

1'. Lâmina foliar esparsamente pilosa ou glabra, face adaxial com tricomas de comprimento menor que o anterior.

2. Lâmina 1,8-8 × 1-5,2 cm; antera com ápice fendido em 2 lobos arredondados...... 2.3. Bertolonia mosenii

2'. Lâmina 5-15,5 × 2,4-7,5 cm; antera com ápice inteiro não fendido.

3. Folhas com base aguda a obtusa e margem serrulada-ciliada; anteras deiscentes por um poro introrso

3'. Folhas com base cordada e margem suavemente crenulada; anteras deiscentes por um poro extrorso. 2.2. Bertolonia margaritacea 
2.1 Bertolonia acuminata Gardner, London J. Bot. 2: 344.1843.

Ervas $20-50 \mathrm{~cm}$ alt. Folhas com pecíolos $2-7$ cm compr.; lâmina 5,7-15,5 ×2,4-6,6 cm, elíptica a lanceolada, base aguda a obtusa, ápice acuminado, margem serrulado-ciliada, ambas as faces com tricomas simples curtos $(0,05-2,3 \mathrm{~mm}$ compr.). Panículas de cimeiras escorpioides 4-12,5 cm compr., terminais. Flores com pedicelo $0,5-1,3 \mathrm{~mm}$ compr.; hipanto 1,2-4 mm compr.; lobos do cálice 1,3-2,6 mm compr.; pétalas 7-10,5 × 4,4-7,5 mm, alvas, largamente ovadas, ápice agudo; estames isomorfos, com filetes $2,2-3 \mathrm{~mm}$ compr., anteras 1,4-2,5 mm compr., ápice não fendido, deiscentes por um poro introrso, apêndice $0,1-0,5 \mathrm{~mm}$ compr., bilobado ou trilobado com ápice arredodado; ovário 1,6-2,5 mm compr., 3-locular, estilete 4-6,5 mm compr. Fruto 6-8,2 $\times 6-9 \mathrm{~mm}$.

Material selecionado: Adrianópolis 9.I.2000, $I$. Isernhagen 238 (MBM, UPCB); Antonina, 9.XII.1998, A.C. Cervi 6579 (UPCB); Guaraqueçaba, 20.III.1999, A.L.S. Gatti 162 (UPCB); Guaratuba, 19.XII.1968, G. Hatschbach 20638 (FUEL, MBM, UPCB); Morretes, 26.X.2005, R. Goldenberg 810 (MBM, UPCB); Paranaguá, 11.I.2002, O.S. Ribas 4243 (MBM); Piraquara, 20.I.1970, G. Hatschbach 23375 (MBM); Quatro Barras, 21.II.1968, C. Koczicki 58 (MBM); São José dos Pinhais, 23.VII.1998, J. Carneiro 512 (MBM).

Bertolonia acuminata ocorre no Rio de Janeiro, Paraná e Santa Catarina (Baumgratz 2015a). Coletada com flores entre dezembro e março, e frutos em março, abril, outubro, novembro e dezembro. A espécie é morfologicamente semelhante a $B$. paranaensis, porém a segunda apresenta tricomas com 6-12 $\mathrm{mm}$ compr. na face adaxial das folhas, enquanto $B$. acuminata possui tricomas de até $2,3 \mathrm{~mm}$ compr.

2.2 Bertolonia margaritacea Naudin, Ann. Gén. Hort. 16: 165. 1867.

Ervas ca. $30 \mathrm{~cm}$ alt. Folhas com pecíolos $1-5,5 \mathrm{~cm}$ compr.; lâmina 5-12,5 × 2,5-7,5 cm, oval ou oval-oblonga, base cordada, ápice agudo, margem suavemente crenulada; face adaxial glabra, geralmente provida de manchas ocelares brancas, face abaxial com projeções glandulares pouco conspícuas. Panículas de cimeiras escorpioides ca. $10 \mathrm{~cm}$ compr., terminais ou axilares. Flores com pedicelo 1,5-3 mm compr.; hipanto ca. $3 \mathrm{~mm}$ compr.; lobos do cálice ca. $4 \mathrm{~mm}$ compr.; pétalas $11 \times 4,5 \mathrm{~mm}$, alvas, obovadas, ápice acuminado; estames isomorfos, com filetes ca. $4 \mathrm{~mm}$ compr., anteras 2,5-3 mm compr., ápice não fendido, deiscentes por um poro extrorso, apêndice dorsal bilobado, um lobo ascendente ca. $0,6 \mathrm{~mm}$ compr., ápice obtuso, outro lobo descendente clavado estreitamente cônico ca. $0,5 \mathrm{~mm}$ compr., ápice agudo; ovário ca. 2,3 mm compr., 3-locular, estilete 3-6 mm compr. Fruto ca. 4,8 $\times 8 \mathrm{~mm}$.

Material examinado: Guaraqueçaba 19.I.1998, G. Gatti et al. 234 (UPCB).

Material adicional examinado: BRASIL. Santa Catarina: Brusque, 5.XII.2009, T.J. Cadorin 532 (UPCB).

Bertolonia margaritacea é encontrada no Rio de Janeiro, São Paulo, Paraná e Santa Catarina (Baumgratz 2015b). Coletada com flores em dezembro e frutos em janeiro. A espécie pode ser reconhecida pela face adaxial da lâmina foliar glabra e geralmente com manchas ocelares brancas.

2.3 Bertolonia mosenii Cogn., Fl. bras. 14(4): 55. 1886.

Ervas $8,3-30 \mathrm{~cm}$ alt. Folhas com pecíolos 0,7-5 cm compr.; lâmina $1,8-8 \times 1-5,2 \mathrm{~cm}$, elíptica a ovada, base aguda a obtusa, ápice agudo a acuminado, margem serrulado-ciliada, ambas as faces com tricomas simples curtos (ca. $1 \mathrm{~mm}$ compr.). Panículas de cimeiras escorpioides 2,3-13 $\mathrm{cm}$ de compr., terminais. Flores com pedicelo 0,6-3 mm compr.; hipanto 1,5-4 mm compr.; lobos do cálice $0,5-2,2 \mathrm{~mm}$ compr.; pétalas 5,7-10 $\times 2,4-6,3 \mathrm{~mm}$, alvas, elípticas a obovadas, ápice agudo; estames isomorfos, com filetes $2-5,5 \mathrm{~mm}$ compr., anteras 1,2-2,5 mm compr., ápice fendido em dois lobos arredondados, deiscentes por dois poros extrorsos, apêndice $0,2-0,5 \mathrm{~mm}$ compr., arredondado; ovário ca. $3 \mathrm{~mm}$ compr., 3-locular, estilete 6,5-8 mm compr. Fruto 3-7,7 ×3,3-10 mm. Material selecionado: Adrianópolis, 17.I.2000 O.S. Ribas 3006 (MBM); Antonina, 26.VIII.1981, G. Hatschbach 43972 (MBM); Campina Grande do Sul, 12.XI.1968, G. Hatschbach 20299 (MBM); Guaraqueçaba, 16.XI.1993, R.X. Lima 159 (UPCB); Guaratuba, 29.XII.1971, G. Hatschbach 28597 (MBM); Morretes, 26.X.2005, R. Goldenberg 804 (MBM, UPCB); Paranaguá, 10.I.2002, O.S. Ribas 4229 (MBM); Quatro Barras, 14.I.1987, R. Kummrow 2846 (MBM); Sete Barras, 12.I.1999, R. Goldenberg 469 (UPCB); Tunas do Paraná, 21.IV.2007, E. Camargo 104 (UPCB).

Bertolonia mosenii é encontrada no Rio Grande do Norte, Minas Gerais, Rio de Janeiro, São Paulo, Paraná e Santa Catarina (Baumgratz 2015a). Coletada com flores entre setembro e março e com frutos de maio a janeiro. A espécie possui as menores dimensões foliares $(1,8-8 \times 1-5,2 \mathrm{~cm})$ entre as espécies do gênero que ocorrem no Paraná 
e pode ser facilmente reconhecida pelas anteras com ápice fendido em dois lobos arredondados.

2.4 Bertolonia paranaensis (Wurdack) Baumgratz, Arq. Jard. Bot. Rio de Janeiro 30: 140. 1990.

Ervas $11-26,5 \mathrm{~cm}$ alt. Folhas com pecíolos 0,5-5 cm compr.; lâmina 4,1-13,5 × 2-6,4 cm, elíptica, às vezes lanceolada, base aguda a obtusa, ápice acuminado, margem serrulada-ciliada, face adaxial com tricomas simples longos (6-12 mm compr.), face abaxial com tricomas simples densos. Panículas de cimeiras escorpioides, 4-12 cm compr., terminais. Flores com pedicelos $0,5-$ 1,7 mm compr.; hipanto 1,8-4 mm compr.; lobos do cálice 1,1-2,5 mm compr.; pétalas 7,5-11,4 × 4-6,5 mm, alvas, elípticas, ápice agudo; estames isomorfos, com filetes 3-4,2 mm compr., anteras 1,7-2,6 mm compr., ápice não fendido, deiscentes por um poro extrorso, apêndice $0,3-0,4 \mathrm{~mm}$ compr., obtuso ou trilobado; ovário 2,1-2,3 mm compr., 3-locular, estilete 5,2-5,4 mm compr. Fruto 4,2-5,6 × 7,1-7,9 mm.

Material selecionado: Antonina, Guaraqueçaba, 7.I.1970, G. Hatschbach 23306 (MBM); 11.IV.2015, L.F. Bacci 154 (UPCB).

Bertolonia paranaensis é encontrada em São Paulo e no Paraná (Baumgratz 2015). Coletada com flores entre novembro e janeiro e frutos em maio e junho. Recentemente encontrada em algumas localidades de Antonina, a espécie não era coletada há 45 anos. Ver comentários em $B$. acuminata.

3. Cambessedesia DC., Prodr. 3: 110. 1828.

Subarbustos com tricomas glandulares ou glabros. Folhas com venação acródroma. Inflorescências paniculadas, dicásio simples ou reduzidas a uma ou duas flores isoladas, longas, apicais ou axilares. Flores 5-meras, diplostêmones; hipanto glabro ou com emergências vascularizadas; cálice simples (desprovido de dentes externos); pétalas completamente amarelas ou vermelho-alaranjadas com base amarela, ovais, ápice acuminado; estames 10 , conectivo desprovido de glândula no dorso, inapendiculado, antera com ápice atenuado. Ovário súpero, com ápice revestido por tricomas glandulares. Frutos capsulares; sementes depresso-ovais.

Cambessedesia é um gênero exclusivo do Brasil, com 23 espécies (Silva-Gonçalves et al. 2015). Ocorre geralmente em domínio de cerrado, em campos rupestres, desde Tocantins, Bahia, Pernambuco, Piauí, Distrito Federal, Goiás, Mato Grosso, Espírito Santo, Minas Gerais até o Paraná (Silva-Gonçalves et al. 2015). No Paraná é representado por duas espécies.

\section{Chave de identificação para as espécies paranaenses de Cambessedesia DC.}

1. Folhas cordadas ou ovais; pétalas amarelas

3.1. Cambessedesia espora

1'. Folhas lanceoladas; pétalas vermelho-alaranjadas com base amarela.

3.2. Cambessedesia hilariana

3.1 Cambessedesia espora (A.St.-Hil. ex Bonpl.) DC., Prodr. 3: 111. $1828 . \quad$ Fig 1g-h Subarbusto $0,3-0,7 \mathrm{~m}$ alt. Folhas com pecíolo ca. 0,6 mm compr.; lâmina 0,5-0,7 ×0,3-0,6 $\mathrm{cm}$, oval ou cordada, base arredondada, ápice acuminado, margem inteira ou denteada. Panículas com raques reduzidas a flores isoladas $4,5-13,3 \mathrm{~cm}$ compr., apicais ou axilares. Flores com pedicelo ca. $3 \mathrm{~mm}$ compr.; hipanto 2,8-3,9 mm compr.; lobos do cálice ca. $1 \mathrm{~mm}$ compr., persistentes; pétalas 3,3-4,2 × 1,6-1,9 mm, completamente amarelas; estames subisomorfos, com filetes 2,9-4,1 mm compr. (antepétalos) ou 2,9-3,4 mm compr. (antessépalos), anteras ca. 3,5 mm compr.; ovário 2-2,5 × 1,5-2 mm, 3-locular, estilete 6,9-9,8 mm compr. Cápsula 3,3-3,9 mm compr.; sementes 0,3-0,4 mm compr.
Material selecionado: Almirante Tamandaré, 27.II.1982, G. Hatschbach 44598 (MBM); Arapoti, 20.XI.1976, G. Hatschbach 39303 (MBM); Bocaíuva do Sul, 19.III.1999, J.M. Silva 2907 (MBM); Jaguariaíva, 3.III.1966, G. Hatschbach 13965 (MBM, UPCB); Sengés, 28.II.1972, G. Hatschbach 29259 (MBM, UPCB).

Material adicional examinado: BRASIL, Minas Gerais: Buenópolis, 09.VI.2004, G. Hatschbach et al. 77643 (UPCB); Conceição do Ibitipoca, 16.XI.2001, F.R.G. Salimena 956(UPCB); Ressaquinha, 12.IX.1964, E. Pereira. 9156 (UPCB);

Cambessedesia espora é encontrada em Goiás, Distrito Federal, Minas Gerais, Rio de Janeiro, São Paulo e Paraná (Silva-Gonçalves et al. 2015). No Paraná ocorre em formações campestres e cerrado. Coletada com flores entre novembro e março, com frutos de fevereiro a março. Suas pétalas inteiramente amarelas distinguem-na 
de C. hilariana e de todas demais espécies de Melastomataceae no estado.

3.2 Cambessedesia hilariana (Kunth) DC., Prodr. 3. 111.1828.

Subarbusto $0,2-0,6 \mathrm{~m}$ alt. Folhas com pecíolo $0,4 \mathrm{~mm}$ compr.; lâmina $0,6-0,8 \times 0,2-0,5 \mathrm{~cm}$, lanceoladas, base atenuada, ápice acuminado, margem inteira ou denteada. Dicásio simples a flores isoladas ca. $4 \mathrm{~cm}$ compr., axilares. Flores com pedicelo 0,7-2 mm compr.; hipanto 4,2-4,8 mm compr.; lobos do cálice ca. 1,6 mm compr., persistentes; pétalas $5,5-5,8 \times 2,6-2,8 \mathrm{~mm}$, vermelho-alaranjadas com base amarela; estames subisomorfos, com filetes 4,6-4,8 mm compr. (antepétalos) ou 3,7-4,8 mm compr. (antessépalos), anteras ca. $6 \mathrm{~mm}$ compr; ovário 3,1-3,7 × 1,8-2 mm, 3-4-locular, estilete ca. $10 \mathrm{~mm}$ compr. Cápsula 5-5,6 mm compr.; sementes ca. $0,7 \times 0,4 \mathrm{~mm}$ compr.

Material examinado: Sengés, 10.X.1958, G. Hatschbach 5072 (UPCB); 7.III.1990, G. Hatschbach et al. 54071 (MBM).

Material adicional examinado: BRASIL, Minas Gerais: Grão Mogol, 13.VI.1990, G. Hatschbach et al. 54236 (MBM); 13.IV.2006, C.V. Vidal 126 (UPCB); Joaquim Felício, 21.X.1999, G. Hatschbach et al. 69443 (UPCB); Ouro Branco, 02.II.2011, F.A. Michelangeli et al. 1569 (UPCB); Presidente Kubitchek, 17.III.1987, G. Hatschbach et al. 51032 (UPCB); Santana do RiachoCardeal, 03.XI.1997, M.A. Farinaccio et al. 91 (UPCB). São Paulo: Itapeva, 29.X.2009, R. Cielo-Filho 1032 (UPCB); Itararé, 13.I.2010, W.S. Mancinelli et al. 1127 (UPCB).

Cambessedesia hilariana é encontrada em Tocantins, Piauí, Pernambuco, Bahia, Goiás, Distrito Federal, Minas Gerais, Espírito Santo, Rio de Janeiro, São Paulo e Paraná (Silva-Gonçalves et al. 2015). No Paraná ocorre em cerrado. Coletada com flores em outubro e frutos em março. Suas pétalas vermelhoalaranjadas, com a base amarela, distinguem-na de C. hilariana e de todas demais espécies de Melastomataceae no estado.

\section{Huberia DC., Prodr. 3: 167. 1828.}

Árvores com tricomas glandulares. Folhas com venação acródroma. Inflorescências cimosas, curtas, apicais. Flores 4-meras, diplostêmones; hipanto glanduloso-pontuado; cálice simples (desprovido de dentes externos); pétalas brancas, com ápice acuminado; estames 8 , conectivo desprovido de glândula no dorso, com apêndice dorso-basal único, filiforme, antera com ápice atenuado. Ovário parcialmente súpero, com ápice glabro. Frutos capsulares; sementes alongadas.
Huberia ocorre no Peru, Equador e Brasil, com 16 espécies (Baumgratz 2004). No Brasil tem distribuição restrita ao domínio de Mata Atlântica, desde Pernambuco até o Rio Grande do Sul (Baumgratz \& Chiavegatto 2015). No Paraná é representado por uma espécie.

4.1 Huberia semiserrata DC., Prodr. 3: 167. 1828.

Fig $1 \mathrm{n}-\mathrm{q}$

Árvores 2-4 m alt. Folhas com pecíolo 1-2 mm compr.; lâmina 3-7 × 1-3 cm, ovadas, obovadas ou elípticas, base aguda, ápice agudo ou acuminado, margem serrulada ou serreada. Cimeiras reduzidas 2-2,8 cm compr., apicais. Flores com pedicelo $1,2-1,7 \mathrm{~cm}$ compr.; hipanto $8-10 \mathrm{~mm}$ compr.; lobos do cálice ca. $6 \mathrm{~mm}$ compr., persistentes; pétalas 25-18 × 10-15 mm, brancas, obovadas, ápice agudo; estames subisomorfos, com filetes 9-11 mm compr. (antepétalos) ou 8-10 mm compr. (antessépalos), anteras ca. 7,5 mm compr., apêndice 3-6 mm compr.; ovário 4,9-5,0 × 2-2,5 mm, 4-locular, estilete ca. 10 mm compr. Frutos não vistos.

Material selecionado: Antonina, 13.XII.1967, G. Hatschbach 18104 (MBM); Guaratuba, 22.XI.1967, G. Hatschbach 17918 (UPCB); 12.XII.1993, J.M. Silva 1286 (UPCB); 13.XII.2009, J. Meirelles 419 (UPCB); Paranaguá, 2.I.1967, G. Hatschbach 15608 (MBM, UPCB).

Huberia semiserrata é encontrada em São Paulo, Paraná, Santa Catarina e Rio Grande do Sul (Baumgratz 2004). No Paraná ocorre em floresta pluvial, na planície litorânea. Coletada com flores entre novembro e janeiro. Huberia semiserrata pode ser reconhecida pelas flores 4-meras e flores com pétalas brancas e estames amarelos, estes com apêndice dorsal alongado.

5. Mouriri Aubl., Hist. Pl. Guiane 1: 452. 1775.

Árvores glabras. Folhas com venação broquidódromas. Inflorescências racemosas, curtas, axilares. Flores 5-meras, diplostêmones; hipanto glabro; cálice simples (desprovido de dentes externos); pétalas brancas, com ápice acuminado; estames 10 , conectivo provido de uma glândula no dorso, com apêndice dorso-basal único, arredondado, antera com ápice arredondado. Ovário ínfero, com ápice glabro. Frutos bacáceos; sementes subesféricas.

Mouriri é um gênero Neotropical, com 86 espécies (Morley 1976; Goldenberg et al. 2013), das quais 54 ocorrem no Brasil (Goldenberg 2015). Tem distribuição predominante na Amazônia, ocorrendo também em Cerrado e Mata Atlântica (incluindo Restinga), com limite ao sul em Santa Catarina. No Paraná é representado por uma espécie. 
5.1 Mouriri chamissoana Cogn. in Mart. \& Eichl., Fl. bras. 14(4): 573. 1888.

Fig 1a-c

Árvores 7-10 m alt. Folhas com pecíolo 1-2 mm compr.; lâmina 4-9 × 2-4 cm, oblongas a lanceoladas, base arredondada a cordada, ápice acuminado, margem inteira ou ondulada. Racemos 1-3,5 cm compr. Flores com pedicelo 6-10 $\mathrm{mm}$ compr.; hipanto 2,5-3 mm compr.; com lobos do cálice ca. $1 \mathrm{~mm}$ compr., persistentes; pétalas $4-5 \times$ 2-3 mm, ovais; estames subisomorfos, com filetes 3-6 mm compr., anteras ca. $2 \mathrm{~mm}$ compr., apêndice ca. $0,5 \mathrm{~mm}$ compr., glândula ca. $0,2 \mathrm{~mm}$ compr., tecas ca. $1 \mathrm{~mm}$ compr.; ovário $5-6 \times 2-2,5 \mathrm{~mm}$, 5-locular., estilete ca. $10 \mathrm{~mm}$ compr. Frutos 10-15 $\mathrm{mm}$ diam.; sementes 7-9 mm diam.

Material selecionado: Antonina, 30.XI.1983, G. Hatschbach 47169 (MBM); Guaraqueçaba, 21.XI.1968, G. Hatschbach 20358 (MBM); Guaratuba, 4.XI.2004, A.C. Cervi 8733 (UPCB); Morretes, 23.XI.1984, F.C. Silva (UPCB 13102); Paranaguá, 2.XI.1965, G. Hatschbach 13081 (MBM, UPCB).

Mouriri chamissoana é encontrada na Bahia, Espírito Santo, Rio de Janeiro, São Paulo, Paraná e Santa Catarina (Goldenberg 2009, 2015). No Paraná ocorre em floresta pluvial, em encostas da Serra do Mar. Coletada com flores em novembro e frutos em fevereiro. Esta espécie é prontamente reconhecida, dentre as Melastomataceae ocorrentes no estado, pela nervação broquidródoma. De fato, Mouriri chamissoana pode ser mais facilmente confundida com espécies de Myrtaceae, do que com Melastomataceae. Os estames em número relativamente pequeno (10), providos de glândula no dorso, distinguem Mouriri das espécies de Myrtaceae ocorrentes no Paraná.

\section{Agradecimentos}

RG recebe bolsa do CNPQ (produtividade em pesquisa); LB e TB recebem bolsa da CAPES (Doutorado). Parte deste trabalho foi financiado pelo CNPQ (Protax 562210/2010-5). As ilustrações foram elaboradas por Diana Carneiro, a quem calorosamente agradecemos.

\section{Referências}

Baumgratz, J.F.A. 1990. O gênero Bertolonia Raddi (Melastomataceae): revisão taxonômica e considerações anatômicas. Arquivos do Jardim Botânico do Rio de Janeiro 30: 69-213.

Baumgratz, J.F.A. 2004. Sinopse de Huberia DC. (Melastomataceae: Merianieae). Revista Brasileira de Botânica 27: 545-561.

BFG. 2015. Growing knowledge: an overview of Seed Plant diversity in Brazil. Rodriguésia 66: 1085-1113.
Buchmann, S.L. 1987. The ecology of oil flowers and their bees. Annual Review of Ecology and Systematics 18: 343-369.

Clausing, G. \& Renner, S.S. 2001. Molecular phylogenetics of Melastomataceae and Memecylaceae: implications for character evolution. American Journal of Botany 88: 486498.

Camargo, E.A. \& Goldenberg, R. 2007. Leandra seção Leandraria (Melastomataceae) no estado do Paraná. Iheringia, Série Botânica 62: 103-111.

Camargo, E.A.; Souza, C.M.F.; Caddah, M.K. \& Goldenberg, R. 2009. O gênero Leandra, seções Carassanae, Chaetodon, Niangae, Oxymeris e Secundiflorae (Melastomataceae) no estado do Paraná. Rodriguésia 60: 595-631.

Cogniaux, A. 1891. Melastomataceae. In: Candolle, A. \& Candolle, C. (eds.). Monographiae Phanerogamarum. Vol. 7. G. Masson, Paris. Pp. 1-1256.

Fritsch, P.W.; Almeda, F.; Renner, S.S.; Martins, A.B. \& Cruz, B.C. 2004. Phylogeny and circumscription of the near-endemic Brazilian tribe Microlicieae (Melastomataceae). American Journal of Botany 91: 1105-1114.

Goldenberg, R. 2004. O gênero Miconia (Melastomataceae) no estado do Paraná, Brasil. Acta Botanica Brasilica 18: 927-947.

Goldenberg, R. 2009. Mouriri Aubl. In: Martins, S.E.; Wanderley, M.G.L.; Shepherd, G.J.; Giulietti, A.M. \& Melhem, T.S. (eds.). Flora fanerogâmica do estado de São Paulo. Instituto de Botânica, São Paulo. Vol. 6, pp. 108-109.

Goldenberg, R. 2014. Melastomataceae. In: Kaehler, M. et al. (eds.). Plantas Vasculares do Paraná. UFPR, Curitiba. Pp. 136-138.

Goldenberg, R.; Almeda, F.; Sosa, K.; Ribeiro, R.C. \& Michelangeli, F.A. 2015. Rupestrea: a new brazilian genus of Melastomataceae, with anomalous seeds and dry indehiscent fruits. Systematic Botany 40: 561-571.

Goldenberg, R.; Bacci, L.F. \& Moraes, J.W. 2015. A tribo Microlicieae (Melastomataceae) no estado do Paraná. Rodriguésia 66: 155-165.

Goldenberg, R.; Baumgratz, J.F.A. \& Souza, M.L.D.R. 2012a. Taxonomia de Melastomataceae no Brasil: retrospectiva, perspectivas e chave de identificação para os gêneros. Rodriguésia 63: 145-161.

Goldenberg, R.; Guimarães, P.J.F.; Kriebel, R. \& Romero, R. 2009. Melastomataceae. In: Forzza R.C. et al. (eds.). Plantas da Floresta Atlântica. Instituto de Pesquisas Jardim Botânico do Rio de Janeiro, Rio de Janeiro. Pp. 330-343.

Goldenberg, R.; Fraga, C.N.; Fontana, A.P.; Nicolas, A.N. \& Michelangeli, F.A. 2012b. Taxonomy and phylogeny of Merianthera (Melastomataceae). Taxon 61: 1040-1056. 
Goldenberg, R.; Meirelles, J. \& Amano, E. 2013. Mouriri morleyii sp. nov. (Melastomataceae) from Brazil, with notes on its foliar stomatal crypts. Nordic Journal of Botany 31: 321-325.

Goldenberg, R.; Souza, C.M.F. \& Dequech, H.B. 2005. Clidemia, Ossaea e Pleiochiton (Melastomataceae) no estado do Paraná, Brasil. Hoehnea 32: 453-466.

Labiak, P.H. 2014. Aspectos fitogeográficos do Paraná. In: Kaehler, M. et al. (eds.). Plantas Vasculares do Paraná. UFPR, Curitiba. Pp. 7-22.

Maack, R. 2012. Geografia física do estado do Paraná. $4^{\mathrm{a}}$ ed. Editora UPGE, Ponta Grossa. 526p.

Martins, A.B.; Goldenberg, R. \& Semir, J. 2009. Flora de Grão-Mogol, Minas Gerais: Melastomataceae. Boletim de Botânica da Universidade de São Paulo 27: 73-96.

Meyer, F.S.; Guimarães, P.J.F. \& Goldenberg, R. 2010. Tibouchina (Melastomataceae) do estado do Paraná, Brasil. Rodriguésia 61: 615-638.

Meyer, F.S. \& Goldenberg, R. 2012. Aciotis, Acisanthera, Marcetia, Microlepis, Pterolepis e Siphanthera (Melastomataceae, Melastomeae) no estado do Paraná, Brasil. Rodriguésia 63: 293-303.

Meyer, F.S.; Meirelles, J.; Caddah, M.K. \& Goldenberg, R. 2012. Novos registros para a família Melastomataceae nos estados do Paraná e Santa Catarina, Brasil. Hoehnea 39: 339-345.

Meyer, F.S. \& Goldenberg, R. 2014. Two new species of Pleroma (Melastomataceae: Melastomeae) from
Brazil. Kew Bulletin 69: 9527. DOI: 10.1007/ S12225-014-9527-8.

Morley, T. 1976. Memecylaceae (Melastomataceae). Flora Neotropica Monograph 15: 1-295.

Renner, S.S. 1993. Phylogeny and classification of the Melastomataceae and Memecylaceae. Nordic Journal of Botany 13: 519-540.

Rodrigues, K.F. 2009. Estudos taxonômicos em Cambessedesia DC. (Melastomataceae). Tese de Doutorado. Universidade Estadual de Campinas UNICAMP, Campinas. 268p.

Schulman, L. \& Hyvonen, J. 2003. A cladistic analysis of Adelobotrys (Melastomataceae) based on morphology, with notes on generic limits within Tribe Merianieae. Systematic Botany 28: 738-756.

Stone, R.D. 2006. Phylogeny of major lineages in Melastomataceae subfamily Olisbeoideae: utility of nuclear Glyceraldehyde3-Phosphate Dehydrogenase (GapC) gene sequences. Systematic Botany 31: 107-121.

Tavares, R.A.M. 2005. Revisão taxonômica do gênero Behuria Cham. (Melastomataceae). Dissertação de Mestrado. Museu Nacional - UFRJ, Rio de Janeiro. 202p.

Thiers, B. 2014. Index Herbariorum: a global directory of public herbaria and associated staff. New York Botanical Garden's Virtual Herbarium. Disponível em $<$ http://sweetgum.nybg,org/ih/>. Acesso em 2 abril 2015.

Lista de exsicatas de Behuria, Bertolonia, Cambessedesia, Huberia e Mouriri do Paraná

Athayde, S.F. 161 (2.3); Bacci, L.F. 154 (2.4), 155 (2.3); Barbosa, E. 241 (2.3), 754 (2.1); Blum, C.T. 575 (2.3); Bochorny, T. 127 (1.1); Caddah, M.K. 705 (2.3); Callejas, R. 1812 (5.1), 1840 (4.1); Camargo, E. 104 (2.3), 128 (2.3), 129 (2.3), 181 (2.1), 183 (2.3), 184 (2.3), 185 (2.3); Carneiro, J. 512 (2.1), 1322 (2.3); Cervi, A.C. 6579 (2.1), 8733 (5.1); Cordeiro, J. 227 (2.1); Fendrich, T.G. 171 (2.3); Gatti, A.L.S. 162 (2.1), 224 (2.1); Gatti, G. 234 (2.2); Goldenberg, R. 469 (2.3), 804 (2.3), 810 (2.1), 2223 (1.1), 2225 (2.4); Hatschbach, G. 873 (2.1), 879 (2.3), 3631 (4.1), 5072 (3.2), 5339 (3.1), 7515 (2.3), 8666 (2.4), 8710 (2.3), 9538 (2.3), 12000 (3.1), 12215 (3.1), 12402 (2.3), 13081 (5.1), 13188, (2.3), 13190 (2.4), 13424 (2.3), 13965 (3.1), 14161 (2.3), 15131 (5.1), $15294(2.3), 15608$, (4.1), 15618 (2.3), 17469 (2.1), 17482 (2.3), 17900 (2.3), 17916 (2.1), 17918 (4.1), 18104 (4.1), $18150(2.3), 18649$ (5.1), 18929 (3.1), 20233 (5.1), 20358 (5.1), 20299 (2.3), 20638 (2.1), 20826 (2.1), 23306 (2.4), 23375 (2.1), 23911(2.1), 26007 (2.3), 28594 (2.1), 28597 (2.3), 29259 (3.1), 31089 (4.1), 33643 (2.4), 39303 (3.1), 41708 (4.1), 43972 (2.3), 44598 (3.1), 47169 (5.1), 47180 (4.1), 47563 (2.3), 48887 (2.1), 54071 (3.2), 54857 (3.1), 56161 (1.1), 58254 (1.1), 58509 (2.1), 58512 (2.3), 72739 (2.3); Hertel, R. 321 (2.1); Isernhagen, I. 238 (2.1), 259 (2.3); Kaehler, M. 134 (2.3); Koczicki, C. 58 (2.1); Kozera, C. 665 (2.3), 696 (2.3). 908 (2.3), 954 (2.3), 1061 (2.1); Kummrow, R. 2846 (2.3), 2961 (2.3); Kuniyoshi, Y. 5547 (2.3); Labiak, P.H. 3468 (2.3); Landrum, L.R. 4002 (2.3); Lima, R.X. 159 (2.3); Lindeman, J.C. 15608 (4.1); Maia, F.R. 110 (1.1); Meirelles, J. 403 (2.3), 419 (4.1.); Motta, J.T. 305 (2.3), 550 (2.1), 909 (2.1); Pasdiora, A.L. 49 (2.1), 50 (2.1), 72 (2.1); Paula, M.F.R. 29 (2.3); Prado, J. 438 (2.3); Reginato, M. 683 (2.3), 705 (2.3), 736 (2.1), 756 (2.1); Ribas, O.S. 965 (2.1), 3006 (2.3), 4229 (2.3), 4243 (2.1); Santos, E.P. 935 (2.1); Sobral. M. 6208 (2.3); Silva, F.C. s.n. UPCB 13102 (5.1); Silva, J.M. 64 (2.3), 1208 (2.1), 1286 (4.1.), 2907 (3.1), 4022 (2.3), 4229 (2.3); Tessmann, G. 3599 (2.3); Vieira, A.O.S. 226 (2.3); Ziller, S.R. 660 (2.3). 